\title{
CURRENT KNOWLEDGE OF BURIED TUNNEL VALLEYS IN DENMARK - MAPPING AND DATA INTERPRETATION
}

Flemming Jørgensen (1) \& Peter B.E. Sandersen (2) (1) - GEUS - Geological Survey of Denmark and Greenland, Department of Groundwater and Quaternary Mapping, Lyseng Alle 1, DK-8270 Højbjerg, Denmark

(2) - Grontmij | Carl Bro, Dusager 12, DK-8200 Århus N, Denmark e-mail : flj@geus.dk, pns@gmcb.dk

A large part of the water supply in Denmark is based on tunnel valley aquifers and the current national groundwater mapping effort is therefore focused on these structures. The preferred geophysical methods are the Transient ElectroMagnetic (TEM) method and the seismic method. The new data collected with these methods bring new geological insight into the uppermost $300 \mathrm{~m}$ of the Quaternary and Tertiary sedimentary succession. Here, numerous, intricate and cross-cutting networks of tunnel valleys are found in most surveyed areas. As the valleys cannot be mapped by using borehole data and seismic data alone, dense grids of data with high lateral resolution are needed to resolve the complicated valley patterns. The TEM method provides the needed data coverage and the valleys appear as a variety of elongated electrical resistivity anomalies. The structural setting of the valleys is exposed in the seismic data, and the valleys appear as erosional structures often with a cut-and-fill setting. Control on the geophysical data is provided by test drillings that brings information about the valley sediments and their sedimentary surroundings.

The collected geophysical and lithological data are continuously evaluated and examined to map and describe the buried valleys. Only when the lateral extent and the orientation of the valleys are properly expressed in the data the valleys are mapped. Therefore, no interpolations between the surveyed areas are made, and the map is therefore considered to represent the minimum occurrence of buried valleys. More than 3,500 $\mathrm{km}$ of buried valleys has presently been mapped. The mapped valleys show signs of a preferred geographical distribution. The tunnel valley density seems to be lower in areas dominated by hydraulically conductive sediments compared to areas dominated by impermeable sediments. The hydraulic conditions of the subsurface are therefore expected to influence the tunnel-valley formation.

The up to $30 \mathrm{~km}$ long valleys are generally between 0.5 and $2 \mathrm{~km}$ wide and up to $350 \mathrm{~m}$ deep. Their long profiles are irregular with depressions and thresholds. The valleys occur in numerous cross-cutting or stacked generations, each of which represents a glacial event with subglacial meltwater erosion, ice retreat and pro-glacial sedimentation. The occurrences of numerous generations of tunnel valleys and interglacial deposits separating the generations indicate tunnel-valley formation during several glaciations throughout the Pleistocene.

The buried tunnel valleys are isolated features which are not interconnected in anastomosing systems. It is unclear whether all valleys in each generation were formed simultaneously or if the individual valleys were formed separately. It is however evident, that many tunnel valleys became ice-filled by creeping ice during the erosion of the bed. Steady subglacial meltwater flow or recurring meltwater releases may continuously have eroded deeper into the substratum followed by ice creep closure of the meltwater channels during periods of decreasing meltwater pressure. 